\title{
Fighting cybercrime through prevention, outreach and awareness raising
}

\section{Laviero Buono}

Published online: 22 January 2014

(C) ERA 2014

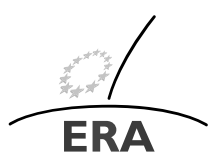

EUROPÄISCHE RECHTSAKADEMIE ACADEMY OF EUROPEAN LAW ACADEMIE DE DROIT EUROPEEN ACCADEMIA DI DIRITTO EUROPEO TRIER - TREVES - TREVIRI

\section{Introduction}

A commonly repeated assertion concerning the internet it is that it is rapidly evolving and that cybercriminals are taking every possible advantages of this. The "mantra" that often follows is that this pace of development poses serious problems to lawmakers who must attempt to catch up with these ever evolving phenomena. This is particularly difficult for European Union (EU) policy-makers since EU policy and legislation is, by definition, a combination (often a culmination, sometimes an accumulation) of agendas, proposals, impact assessments and revisions.

According to the International Telecommunication Union (ITU), the specialised agency for information and communication technologies of the United Nations, in 2013 over 2,7 billion people regularly made use of the internet. This corresponds to almost $40 \%$ of the world's population. The spread of mobile broadband continued to grow, with more than 2 billion subscriptions worldwide by the end of 2013. ${ }^{1}$ There is little doubt that the increase in global connectivity is inseparably tied to the development of contemporary cybercrime in its various forms: on-line fraud, on-line child sexual exploitation, attacks against critical infrastructures and information systems, etc.

The enablers of cybercrime are various. First, in relation to the issue of perceived anonymity, individuals are capable of committing crimes in cyberspace that they

\footnotetext{
${ }^{1}$ International Telecommunication Unit “The World in 2013-ICT Facts and Sheets”, February 2013.
}

All comments and views expressed in this article are those of the author alone.

L. Buono, Head of Section for European Criminal Law ( $\varangle)$

Academy of European Law (ERA), Trier, Germany

e-mail: lbuono@era.int 
would not otherwise commit in the physical off-line world. Second, the "commodity" that is offered by internet infrastructures and platforms, including the emergence of on-line social networks, for example, has provided a readily available supply for millions of potential frauds and phishing attacks. Users tend to organise their social networking profiles according to their interests and locations, thereby enabling criminals to target victims in light of their behavioural patterns and backgrounds. Third, the fragmentation at international level and the diversity of national cybercrime legislation and frameworks has had, as a consequence, the germination of a plethora of different international instruments aimed at combating cybercrime being promulgated in the past years. On a European level, it is worth mentioning the 2001 Council of Europe Convention on Cybercrime, ${ }^{2}$ the 2007 Council of Europe Convention on the Protection of Children against Sexual Exploitation and Sexual Abuse, ${ }^{3}$ the 2011 EU Directive on combating the sexual abuse and sexual exploitation of children and child pornography ${ }^{4}$ and the 2013 EU Directive on attacks against information systems. ${ }^{5}$ However, a clear, comprehensive and harmonised framework is still lacking. Finally, another key factor is the "low risk" perception associated with cybercrime. The proportion of cybercrimes detected through investigation remains very low. According to the 2013 Study conducted by the United Nations Office on Drugs and Crime (UNODOC), responding countries estimated that the reporting of cybercrimes to the police by victims was in the range of slightly upwards of 1 per cent. ${ }^{6}$

Legal measures certainly play a vital role in combatting cybercrime and should address different areas, ranging from substantive to procedural criminal law, as well as encompassing jurisdictional issues. At any rate, comprehensive policy strategies should also be established. The next sections will focus on three specific categories of policy strategy that could help the fight against cybercrime: prevention through threat assessments, outreach and awareness raising.

\section{Preventing cybercrime through threat assessments and strategic analysis}

Strategic intelligence and analysis is vital in the fight against cybercrime. In methodological terms, this mainly consists of data gathering, interpretation thereof and speculative considerations on future developments, patterns, trends, threats and opportu-

\footnotetext{
${ }^{2}$ Council of Europe Convention on Cybercrime (ETS 185) and the Protocol on Xenophobia and Racism (ETS 189).

${ }^{3}$ Council of Europe Convention on the Protection of Children against Sexual Exploitation and Sexual Abuse (CETS 201).

${ }^{4}$ Directive 2011/92/EU of the European Parliament and of the Council of 13 December 2011 on combating the sexual abuse and sexual exploitation of children and child pornography, and replacing Council Framework Decision 2004/68/JHA (OJ L 335/1 of 17.12.2011).

${ }^{5}$ Proposal for Directive of the European Parliament and the Council on Attacks against Information Systems, replacing Council Framework Decision 2005/222/JHA-General Approach (Council of the EU, Interinstitutional file 2010/0273 COD).

${ }^{6}$ United Nations Office on Drugs and Crime (UNODOC) "Comprehensive Study on Cybercrime", February 2013, p. 117.
} 
nities. ${ }^{7}$ Strategic intelligence applied to cybercrime ultimately attempts to give an answer to the question: "What can we about the current and future threats at a practical level?".

Europol recently adopted a very well structured strategic analysis methodology in the framework of its first Serious and Organised Crime Threat Assessment (SOCTA). ${ }^{8}$ Such methodology, generally constructed to analyse the threat posed by serious organised groups, can be, mutatis mutandis, used to scrutinise the specificities of the cybercrime threats.

In fact, the SOCTA methodology ${ }^{9}$ aims to analyse the threatening features of organised crime groups (OCGs) ${ }^{10}$ the threatening features of serious and organised crime (SOC) areas and their geographical dimension. In so doing, crime-relevant factors (CRF) such as the economic crisis, transportation and logistics, corruption in the public sector, access to internet, etc. are also taken into account. Ultimately, once analysed, these indicators, factors and enablers will lead to a more complete picture of the current trends and forecast future threats. In a final step, a series of recommended priorities are then formulated.

This scheme, applied to the cybercrime phenomenon, will allow, first and foremost, a clearer picture of the gangs involved in cybercrime modi operandi and cybercriminals' motivations. It will allow us to assess indicators such as the size of the cybercrime group, the financial recourses available, the expertise, the international dimension of their activities, the flexibility, the internal structure of the group, etc.

As an example, recent strategic analysis carried out in the field of on-line child sexual exploitation, tells us that individuals with a sexual interest in children and compulsive qualities in relation to their internet usage appear to create networks and "environments". Moreover, they are increasingly making use of hidden services, anonymisers and encryption software. ${ }^{11}$ The analysis also indicates that only a very small amount of child abuse material is now actually being purchased (approximately $10 \%)^{12}$ due to the wide availability of free material, especially via peer-to-peer technology and file sharing. Going beyond the offenders, national threat assessments ${ }^{13}$ provide key information on the victims of child sexual exploitation. The vast majority of them are predisposed to being vulnerable to exploitations due to problems

\footnotetext{
${ }^{7}$ Don McDowell: "Strategic Intelligence-A Handbook for Practitioners, Managers and Users", The Scarecrow Press, Inc., 2009.

${ }^{8}$ Europol: "EU Serious and Organised Crime Threat Assessment-SOCTA 2013", 2013.

${ }^{9}$ The full methodology, validated by COSI in its meeting of 25 June 2012, can be found in the public document of the Council of the European Union: "Serious and Organised Crime Threat Assessment (SOCTA)—methodology" (Brussels, 4 July 2012, 12159/2 Limite).

${ }^{10}$ The SOCTA uses the definition of international organised crime provided by the 2008 EU Framework Decision on organised crime (Council Framework Decision 2008/841/JHA of 24 October 2008 on the fights against organised crime, OJ L 300, 11.11.2008, p. 42).

${ }^{11}$ Virtual Global Taskforce: "Environmental Scan 2012”, prepared by the European Cybercrime Centre (EC3), Europol.

${ }^{12}$ Virtual Global Taskforce: "Environmental Scan 2012", prepared by the European Cybercrime Centre (EC3), Europol, p. 15.

${ }^{13}$ Child Exploitation and Online Protection Centre (CEOP): "Threat Assessment of Child Sexual Exploitation and Abuse", June 2013.
} 
such as the consumption of alcohol and drugs, mental health issues, regular episodes of truancy or unpermitted absence, living in local authority care or being known to the police and/or social services. The most prominent victim age group seems to be children aged between 14 and $15 .^{14}$

Moving away from child sexual exploitation and approaching the cybercrime phenomenon as such, strategic forecasts seem to predict for the future cyber attacks targeting mobile devices and cloud computing platforms. Moreover, there also seems to be a new danger, referred to as the "Bring Your Own Device" (BYOD) trend, i.e. the possibility given to employees to bring personally owned mobile devices (laptops, tablets, and smart phones) to their workplace and to use those devices to access company data. This presents a further appealing target for cybercriminals who could then hack into a digital portable device and steal, manipulate and misuse not only personal information of the individual but also the corporate data of his/her company. ${ }^{15}$

All this information and these trends play a vital role in guiding the policy-making process. They will also serve to strategically plan operations in line with ad hoc policy action plans. ${ }^{16}$ Lack of reporting of crimes results in a small number of international investigations and a low level of prioritisation within law enforcement authorities and prosecution services. If the problem is not reflected in statistics and cases reported/investigated, the phenomenon will continue to be neglected when priorities are being set, with consequent implications for forward-planning budget allocation. To this extent, working on the analysis of cybercrime indicators, scanning the horizon so that future threats can be defined and recommending priorities in light of newly emerged cybercrime enablers would seem to constitute some of the necessary bases on which policy and law-makers should plan, re-define or even launch brand new instruments and tools.

\section{Outreach and international cooperation}

The internet has made geographic considerations less relevant, if not indeed totally irrelevant. This has stimulated a higher degree of international criminal activities for which airports, transport routes and other physical land, sea or air infrastructures are no longer necessary. Cyber criminality knows no borders and it is just one click away. This requires law enforcement authorities to adopt a holistic approach across countries, together with public and private stakeholders alike. There are numerous forces that can contribute to a more effective fight against cybercrime: national governments, international organisations and bodies, internet governance bodies and service

\footnotetext{
${ }^{14}$ Child Exploitation and Online Protection Centre (CEOP): "Threat Assessment of Child Sexual Exploitation and Abuse", June 2013, p. 20.

${ }^{15}$ Europol: "EU Serious and Organised Crime Threat Assessment-SOCTA 2013", 2013, p. 28.

${ }^{16}$ The SOCTA 2013 is only the starting point of the EU policy cycle which will last for four years and will be structured, after SOCTA, in another three steps: the Multi-Annual Strategic Action (MASP), the Multidisciplinary Platform against Criminal Threats (EMPACT) and the final review and assessment. For more see: Council Conclusions on the creation and implementation of an EU policy cycle for organised and serious international crime (15358/10 COSI 69 ENFOPOL 298 CRIMORG 185 ENFOCUSTOM 94).
} 
providers, companies involved in internet security and the financial sector, academic experts and civil society organisations. However, a focal point is needed.

Within the EU this role has recently been given to the European Cybercrime Centre (EC3), ${ }^{17}$ which, following its launch in January 2013, is set to become the EU's collective voice in fight cybercrime. The EC3 will support operations, it will be active in research, training and prevention, and it will regularly liaise with a number of EU agencies and bodies. ${ }^{18}$ The establishment of the EC3 at EU level mirrored the launch of the Interpol Global Complex for Innovation, in Singapore. ${ }^{19}$ These centres will work together closely with the private sector and the internet industry as a whole. ${ }^{20}$ Today the fight against cybercrime is unthinkable without ensuring a regular dialogue with the service providers ultimately preserving the evidence that can help to identify potential perpetrators, with the social networking sites where billions of photos and messages are exchanged every day and, with the security technology firms that build up products to make our devises safer and less exposed to newly detected viruses and worms.

In 2008, the Council of Europe issued the "Guidelines for the cooperation between law enforcement and internet service providers against cybercrime". ${ }^{21}$ These guidelines prescribe that law enforcement and internet service providers should promote a culture of cooperation rather than confrontation, including the sharing of good practices. Regular meetings in order to exchange experiences and resolve problems are encouraged.

Finally, explicit reference to international cooperation is contained in the newly adopted 2013 EU Cybercrime Directive which aims, inter alia, to strengthen networks such as the G8 and Council of Europe's network of contact points, who are available on a twenty-four hour, seven-day-a-week basis (24/7 network). The aim is to render law enforcement cooperation and intelligence sharing more effective, to expedite smooth communication and to keep apace with the speed at which large-scale cyber attacks can be perpetrated.

Building trust and confidence between the internet industry and public sector authorities is of utmost importance in fighting cybercrime. Networks and trusted data exchange platforms should be built with the private sector and other actors such as the research community and civil society. The EC3 and the Global Complex for Innovation (at European and at global level respectively) can now act as catalysts to

\footnotetext{
${ }^{17}$ Communication from the Commission to the Council and the European Parliament-Tackling Crime in our Digital Age: Establishing a European Cybercrime Centre (COM(2012) 140 final, 28.3.2012).

${ }^{18}$ More information on the European Cybercrime Centre (EC3) can be found on: https://www.europol. europa.eu/ec3.

${ }^{19}$ More information on the INTERPOL Global Complex for Innovation can be found on: http://www.interpol.int/About-INTERPOL/The-INTERPOL-Global-Complex-for-Innovation.

${ }^{20}$ This seems to be adequately stressed by the Communication on the establishing of the EC 3 that clearly states: "Building trust and confidence between the private sector and law enforcement authorities is of utmost importance in the fight against cybercrime".

${ }^{21}$ Council of Europe: "Guidelines for the cooperation between law enforcement and internet ser-

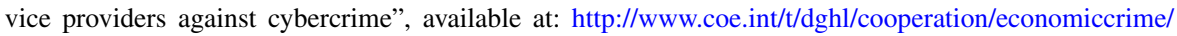
cybercrime/Documents/Reports-Presentations/567_prov-d-guidelines_provisional2_3April2008_en.pdf.
} 
collect these voices and better prevent cybercrime as well as to plan and coordinate operational activities in this area.

\section{Awareness raising and training}

The need to educate internet users on how best to utilise technologies cannot be delayed anymore. Combating cybercrime is not a prerogative that rests on law enforcement authorities alone. Proper, well-structured awareness programmes for internet users should be conceptualised.

The recent 2010 EU Communication "A digital agenda for Europe" states:

Europe is suffering from a growing professional ICT skills shortage and a digital literacy deficit. These failings are excluding many citizens from the digital society and economy and are holding back the large multiplier effect of ICT take-up to productivity growth. This requires a coordinated reaction, with Member States and other stakeholders at its centre. ${ }^{22}$

National governments should launch publicity campaigns to help people protect themselves against on-line crime. Simple security precautions, especially among youngsters, could considerably reduce cybercrime. Awareness raising via sustained media campaigns, television adverts and ad hoc websites is just one option to achieve this aim. Ultimately, better public information about computer safety could not only save huge numbers of people from the hassle of having their data stolen but also from becoming a direct physical victim of cybercrime (as in the case of child sexual exploitation). The 2012 Special Cyber Security Eurobarometer found that $74 \%$ of EU citizens shared the opinion that the risk of becoming a victim of cybercrime has increased in the past years. The vast majority of internet users agree that they avoid disclosing personal information on-line $(89 \%) .^{23}$

Turning now from the general public awareness raising to the specific cybercrime alertness among EU legal practitioners, the acquisition of adequate skills to deal with internet-related offences in concrete criminal proceedings would seem essential for legal practitioners. In the aftermath of the Hague Programme of November $2004^{24}$ and its subsequent Commission Action Plan, ${ }^{25}$ the Stockholm Programme 20102014 also attributed great importance to training. Paragraph 1.2.6 of this stated:

[I]n order to foster a genuine European judicial and law enforcement culture, it is essential to step up training on European Union-related issues and make it

\footnotetext{
${ }^{22}$ Communication from the Commission to the European Parliament, the Council, the Economic and Social Committee and the Committee of the Regions: "A Digital Agenda for Europe" (COM(2010)245 final, 19.05.2010).

${ }^{23}$ Special Eurobarometer 390 "Cyber Security”, European Commission, Directorate-General for Communication (July 2012), available at: http://ec.europa.eu/public_opinion/archives/ebs/ebs_390_en.pdf.

${ }^{24}$ Presidency Conclusions-Brussels, 4 and 5 November 2004.

${ }^{25}$ Communication from the Commission to the European Parliament-The Hague Programme: Ten priorities for the next five years. The Partnership for European renewal in the field of Freedom, Security and Justice (COM (2005) 184 final).
} 
systematically accessible for all professions involved in the implementation of the area of freedom security and justice. This will include judges, prosecutors, judicial staff, police and customs officers and border guards. ${ }^{26}$

Training on cybercrime can be offered at three different levels: (a) introductory courses (offering basic knowledge and understanding of cybercrime, the risks associated with the information and communication technologies, trends in cybercrime, types of cybercrime and main tools utilised, legal challenges at national, European and International level); (b) advanced investigators' courses (identifying and tracing computer-related crimes, investigative tools and strategies, search and seizure, forensic interrogation of computers and related devices, investigation and control of cybercrime, oversight and management of cases involving cybercrime) and (c) advanced forensic specialists' courses (acquiring forensic images in accordance with acknowledged principles and methodology, recognising and resolving technical issues, products of analytical procedures, performing the role of the expert in investigations and in court).

Basic courses should be offered to judges in order to familiarise them with fundamental cybercrime concepts such as "botnet", "Denial of Service Attacks" or "DOS", "phishing" and others. Without such a basic understanding and awareness, the possibilities for success of even very well investigated and prosecuted cyber-cases risk being jeopardised in trials. Due to the cross-cutting nature of cybercrime, whatever the specialisation of the judges and prosecutors may be (whether it be a procedure in the financial and banking sector, or in the telecommunications area, the fight against organised crime and terrorism, the sexual exploitation of children, etc.), it is imperative that they are equipped with at least a basic understanding of the phenomenon of cybercrime. It is equally important to regularly organise advanced courses for cyber investigators and forensic analysts, who, having already digested the basic rules and key concepts, need continuous updates on current trends, threats, methodologies and techniques in this rapidly expanding and developing area.

\section{Conclusions}

Criminals always seem to be one step ahead when it comes to exploiting high-tech facilities for illegal purposes. Nevertheless, it has to be acknowledged that numerous bodies and organisations are working on initiatives in order to coordinate the efforts in fighting cybercrime. These initiatives range from new legislation to the establishment of new bodies, as the recent setting up of the EC3 within Europol in The Hague and the Interpol Global Complex for Innovation, in Singapore, have demonstrated.

However, the fight against cybercrime needs a comprehensive policy approach. Such an approach should take into account cybercrime forecast trends in order to prevent new threats and to help ensure that adequate preparations are made in advance. Prevention should be accompanied by an outreach approach. Cybercrime cannot be

\footnotetext{
${ }^{26}$ The Stockholm Programme-An open and secure Europe serving and protecting the citizens, Presidency Conclusions-Brussels, 10-11 December 2009 (Council of the European Union, Brussels 3 March 2010, doc 5731/10, p. 16).
} 
fought by law enforcement authorities alone. There is a clear need for them to establish dialogues at a vertical level (with prosecutors and judges) and at a horizontal level (with the internet industry, with other stakeholders and the civil society as a whole). Finally, awareness raising and continuous training are needed at all levels. Raising the overall awareness of the threat of cybercrime, especially among consumers and other vulnerable groups of potential victims, while avoiding undermining the trust of internet users by focussing exclusively on the potential dangers inherent in making use of the web, remains a key challenge for the years ahead. 